\title{
Information for Participants
}

\section{Conference Desk}

\section{Event and Venues}

The desk will be located in the hall of the Palazzo dei Congressi throughout the conference. It will be open from 17.00 to $20.00 \mathrm{~h}$ on Wednesday, September 29 and thereafter, from 08.00 to $18.30 \mathrm{~h}$ daily. On Saturday, October 2, the opening time will be from 8.00 to $14.00 \mathrm{~h}$.

The conference desk can be contacted by phone (0041 9191104 31), during the conference hours.

Urgent fax messages can be sent to delegates (0041 9179620 43).

Lectures will be held in the Palazzo dei Congressi, Auditoriums A, B and C.

Posters will be displayed in the hall of the Palazzo dei Congressi. They should measure $1.20 \mathrm{~m}$ high by $1 \mathrm{~m}$ wide and may be mounted from Thursday morning, September 30; they should be removed by $18.30 \mathrm{~h}$ on Friday, October 1 .

Coffee Break in the Palazzo dei Congressi

\section{Farewell Dinner}

Friday, October 1, 20.30 h, Ristorante Capo San Martino, Lugano Paradiso. Buses will be organized from Lugano Palazzo dei Congressi to Paradiso. 